\title{
Cross-Cultural Adaptation and Measurement Properties of the Brazilian Portuguese Version of Two Scales Which Measure Function and Disability in People with Achilles Tendinopathy
}

\author{
Y. A. Bandeira Murakawa ${ }^{2,3}$, S. F. Chaves Coêlho Ferreira', ${ }^{2,3}$ M. L. Azevedo Tavares ${ }^{3}$, \\ M. Almeida Bezerra ${ }^{1,2,3}$, R. Ribeiro de Oliveira ${ }^{1,2,3}$ \\ 1 Department of Physical Therapy, Federal University of Ceará, Fortaleza, Ceará, Brazil \\ 2 Tendon Research Group- Brazil, Fortaleza, Ceará, Brazil \\ 3 Master Program in Physiotherapy and Functioning, Federal University of Ceará, Fortaleza, Ceará, Brazil
}

\section{CORRESPONDING AUTHOR:}

Rodrigo Ribeiro de Oliveira

Department of Physical Therapy

Federal University of Ceará

Rua Major Wayne 1440

Fortaleza, Ceará, Brazil

E-mail: rodrigo@ufc.br

DOI:

10.32098/mltj.02.2021.08

LEVEL OF EVIDENCE: 3B

\section{SUMMARY}

Background. Achilles tendinopathy can be disabling and is one of the most common chronic lesions among conditions affecting athletes' feet and ankles. The clinical recommendation to measure self-reported limitations and functional capacity of patients with Achilles tendinopathy suggests the use of the Victorian Institute of Sport Assessment-Achilles (VISA-A) for pain and stiffness and the Foot and Ankle Ability Measure (FAAM) or the Lower Extremity Functional Scale (LEFS) to assess activity and participation. The Tendon Grading System and the Classification System for the Effect of Pain on Athletic Performance together measure the basic outcomes of VISA-A, FAAM, and LEFS, but is short, concise, and can be applied quickly in clinical practice. However, the scales were not adapted and validated for a Brazilian Portuguese version. The purpose of the present study is to validate and culturally adapt these scales to the Brazilian Portuguese language.

Methods. A cross-cultural adaptation and validation study were performed. The recommendations presented on standardized methods for the cross-cultural adaptation of self-administered questionnaires was followed. The recommendations define this process in six phases: translation, synthesis, back translation, expert committee review, pretesting, and a Delphi study to obtain the consensus of a group of experts on the quality of translation. The construct validity was tested in 17 non-athletes and asymptomatic participants, 50 amateur and professional athletes who are practitioners of modalities that place a great demand on the Achilles tendon, and 39 amateur and professional athletes diagnosed with Achilles tendinopathy.

Results. The Spearman correlation between the Tendon Grading System and VISA-ABr was - $0.79(p=0.001)$; between Tendon Grading System and LEFS, - $0.72(p=0.001)$; and between Classification System for the Effect of Pain on Athletic Performance and LEFS - $0.68(\mathrm{p}=0.001)$, demonstrating a strong correlation in both comparisons. The results between Classification System for the Effect of Pain on Athletic Performance and VISA-A-Br were - $0.81(\mathrm{p}=0.001)$, indicating a very strong correlation.

Conclusions. The Tendon Grading System and Classification System for the Effect of Pain on Athletic Performance are similar to their original versions. The scales were valid for assessing pain and stiffness (Tendon Grading System) and activity and participation (Classification System for the Effect of Pain on Athletic Performance) in a Brazilian population with Achilles tendinopathy.

\section{KEY WORDS}

Achilles tendinopathy; activity; pain; participation; patient reported outcome. 


\section{BACKGROUND}

Achilles tendinopathy can be disabling and is reported as one of the most common chronic lesions among the conditions affecting athletes' feet and ankles (1). The annual incidence of Achilles tendinopathy in runners is 7 to $9 \%$ (2), and in soccer players a new case occurs every 4000 hours of training (3). It can also occur in sedentary individuals, affecting about $30 \%$ of this population (4). The overall incidence of Achilles tendinopathy is approximately 1.85 per 1000 people (5). The clinical recommendation to measure self-reported limitations and functional capacity of patients with Achilles tendinopathy suggests the use of the Victorian Institute of Sport Assessment-Achilles (VISA-A) for pain and stiffness (6). The Foot and Ankle Ability Measure (FAAM) or the Lower Extremity Functional Scale (LEFS) are suggested to implement to assess activity and participation in patients with Achilles tendinopathy $(6,7)$. In addition to assessing the effectiveness of the proposed intervention using standardized instruments, these measures are important for comparing individual and collective results (6). The VISA-A was recently adapted and the Brazilian version validated (VISA-A-Br) (8). The VISA-A-Br had good internal correlation, good test-retest validity (ICC2.1 $=0.84$ ), and good construct validity when compared to the LEFS (Spearman's coefficient with LEFS = 0.73) (8).

Besides that, The Tendon Grading System and Classification System for the Effect of Pain on Athletic Performance are potential instruments for use in clinical practice. The scales were cited in the English (7), Swedish (11) and German (12) versions of VISA-A, although their original version had not been validated in other languages. The Tendon Grading System (9) uses an ordinal variable that grades pain and function levels as excellent, good, reasonable, and poor. The Classification System for the Effect of Pain on Athletic Performance (10) evaluates the influence of tendon pain on limitations in sports performance and classifies this influence at six levels, ranging from no pain and unrestricted performance to pain during activities of daily living and the inability to play sports (12). The Tendon Grading System has the potential to measure pain and function in participants with Achilles tendinopathy and the Classification System for the Effect of Pain on Athletic Performance to measure the impact on the activity and performance of participants with Achilles tendinopathy. Together, the scales measure the basic outcomes of VISA-A, FAAM, and LEFS but is short, concise, and can be applied quickly in clinical practice. However, the Tendon Grading System and Classification System Scales for the Effect of Pain on Athletic Performance were not adapted and validated for a Brazilian Portuguese version. Thus, due to the use of the Tendon Grading System and Classifica- tion System for the Effect of Pain on Athletic Performance in international studies of versions of VISA-A and its potential to aggregate information on pain, function, and limitations in sports activity, the purpose of the present study is to validate and culturally adapt these scales to Brazilian Portuguese.

\section{MATERIALS AND METHODS}

The study procedures were carried out according to the ethical standards of the journal (13). We conducted the study at the Federal University of Ceará with the Research Group of Prevention, Evaluation, and Intervention in Tendon Alterations (Tendon Research Group-Brazil). The study protocol was approved by the research ethics committee following all due procedures.

\section{Cross-cultural adaptation}

The process of cross-cultural adaptation followed the recommendations of international guidelines (translation, synthesis, back translation, expert committee review, pretesting) (14). We added a Delphi study with to obtain the consensus of a group of experts on the quality of translation and finally, the scales were tested with 15 university students who pointed out possible difficulties in understanding items on the scales. If three or more college students, representing $15 \%$, noted a particular difficulty on a scale it would be reviewed and applied again. And so, we get the final version of the translations (figures 1, 2).

\section{Sample}

The study included 105 active participants, both men and women. The participants were between 18 and 60 years of age and participation in various sports. The sample was classified according to the level of participation in sports in general, the level of participation in sports with a high risk of developing Achilles tendinopathy, and the presence of Achilles tendinopathy. According to these criteria, three groups were formed. The control group included participants who were physically active, non-athletes and asymptomatic for Achilles tendinopathy $(n=17)$. The risk group included amateur and professional athletes asymptomatic for Achilles tendinopathy and practitioners of modalities that place greater demands on the Achilles tendon (n $=50$ ). The tendinopathy group was composed of amateur and professional athletes diagnosed with Achilles tendinopathy $(\mathrm{n}=39)$. Participants were recruited in amateur and professional sports clubs, training centers, dance companies, orthopedic outpatient clinics, physiotherapy clinics. Individuals were recruited by direct contact and responded 
to self-administered Tendon Grading System and Classification System for the Effect of Pain on Athletic Performance VISA-A-Br and LEFS. All participants were informed about the objectives, risks, and benefits of participating in the research and signed a free and informed consent form. Personal data such as name, age, gender, type of activity, and medical diagnosis (if any) were then collected.

We take into account the clinical history of pain reported with the Achilles tendinopathy associated with calcaneal tendon overload by sports practice was taken into account when characterizing the participants with Achilles tendinopathy. In addition, participants with Achilles tendinopathy had pain by palpation in the medial portion $(2-6 \mathrm{~cm}$ proximal to the insertion) (15), and/or a nosological diagnosis by an orthopedic specialist in the area, which may or may not have been accompanied by complementary tests such as ultrasonography and magnetic resonance imaging. We considered as asymptomatic participants for Achilles tendinopathy if they did not present spontaneous complaints of pain and stiffness in the region of the calcaneal tendon and obtained a negative result in the palpation test of the calcaneal tendon. Subjects who presented bilateral tendinopathy of the calcaneus were excluded from the study. Also excluded, those with any musculoskeletal lesion on the lower limbs, low back pain with radiculopathy, or surgery on the lower limbs.

\section{Collection of data and instruments used}

After the participants signed the free and informed consent form (TCLE), we completed a brief questionnaire and we performed a physical evaluation to identify the participants with Achilles tendinopathy. Then, the Tendon Graduation System and Classification for the Effect of Pain on Athletic Performance scales and the VISA-A-Br (8) and LEFS (16) were distributed.

The Tendon Graduation System is an ordinal variable scale. The scale classifies the tendon as excellent if there is total function and no residual disability; good if there is total function, no disability and minimal pain; reasonable if there are some limitations during activities; and bad if there is severe weakness and marked lameness (9).

The Classification for the effect of pain on athletic performance is a continuous variable scale that classifies the influence of pain on the limitation of athletic performance at six levels. The scale defines level 1 as no pain and unrestricted performance. Level 2 occurs if there is pain with extreme exertion and unrestricted performance. Level 3 occurs if there is pain with extreme exertion or after 1 or 2 hours of activity with normal or slightly reduced performance. Level 4 occurs if there is pain during and after vigorous activity and reduced performance. Level 5 occurs if there is pain during sports activity, forcing an interruption with a marked decrease in performance. Level 6 occurs if there is pain during daily life activity and the inability to participate in sports (10).

The VISA-A-Br is a self-administered scale that assesses the intensity of symptoms and their impact on the individual's physical activity. The VISA-A-Br consists of eight questions. Questions 1 to 3 are about pain, 4 to 6 about function, and 7 and 8 about activity. Six questions are scored using a Likert scale, ranging from 0 to 10 . Question 7 is scored on a Likert scale, but with four possible answers, $0,4,7$, or 10 . The eighth question is divided into three items, but only one is answered. The item is chosen according to the perception of pain during sports activities, and the score can range from 0 and 30 . The total score of the scale varies between 0 and 100 points. A score of 0 represents the highest severity of the disease, and 100 represents no pain or dysfunction (8). The LEFS scale is self-applied and assesses the function of the lower limbs related to activities and tasks. LEFS can be used in various musculoskeletal conditions, such as Achilles Tendinopathy. The scale consists of 20 items graded on a Likert scale ( 0 to 4 points). The total score ranges from 0 to 80 points. A score of 80 represents the best possible function (16).

\section{Properties of measurements}

We defined the measurement properties according to the COSMIN manual (17) and Terwee et al. (18). We have previously defined four hypotheses for construct validity: 1) Moderate to strong correlation between the Tendon Grading System and LEFS; 2) Moderate to strong correlation between Classification System for the Effect of Pain on Athletic Performance and LEFS; 3) Very strong correlation between Tendon Grading System and VISA-A-Br; 4) Very strong correlation between Classification System for the Effect of Pain on Athletic Performance and VISA-A-Br. We categorize the correlation force according to the classification: very weak (0.0-0.19); weak (0.2-0.39); moderate (0.4$0.59)$; strong (0.6-0.79); and very strong (> 0.8) (19). Good construct validity was based on meeting the criteria in at least $75 \%(3 / 4)$ of the indicated hypotheses (17).

\section{Statistical analysis}

We used the software packages SPSS Version 20 (IBM Corporation, Armonk, NY) and to perform the statistical analyzes. The construct validity was tested by correlating the translated Tendon Grading System and Classification System for the Effect of Pain on Athletic Performance 
with the VISA-A-Br and LEFS, calculating the Spearman correlation (@). The Spearman correlation was applied to evaluate the monotonic relationship between two ordinal variables.

\section{RESULTS}

\section{Cross-cultural adaptation and consensus}

We did not experience any conflicts during the phases of cross-cultural adaptation. We obtained 10 responses from experts in the Delphi study and the agreement rate was between 80 and $100 \%$ on the translation of the Tendon Grading System and Classification System for the Effect of Pain on Athletic Performance scales. No volunteers reported difficulty in understanding the scales. The results of the cross-cultural adaptation of the scales is found in figures 1 and $\mathbf{2}$.

\section{Characterization of the sample}

A total of 105 volunteers were included in the study. The data is presented in table $\mathbf{I}$. The groups were composed of individuals who participated in basketball $(24.8 \%)$, running $(14.3 \%)$, soccer $(12.4 \%)$, and other modalities ranging from $1 \%$ (CrossFit) to $11.4 \%$ (volleyball).

\section{Construction validity}

The Spearman correlation between the Tendon Grading System and VISA-A-Br was - $0.79(\mathrm{p}=0.001)$, and between Tendon Grading System and LEFS - $0.72(\mathrm{p}=0.001)$ (table II), demonstrating there is a strong correlation in both comparisons. The Spearman correlation between Classification System for the Effect of Pain on Athletic Performance and VISA-A-Br was - $0.81(\mathrm{p}=0.001)$, indicating a very strong correlation. Between Classification System for

\section{Sistema de graduação do tendão}

$\square$ Excelente: função total e nenhuma incapacidade residual

Bom: função total, nenhuma incapacidade e com dor mínima

Razoável: algumas limitações durante atividades

$\square$ Ruim: apresenta fraqueza severa e claudicação acentuada

Figure 1. Final version of Tendon Graduation System.

\section{Sistema de classificação para o efeito da dor no desempenho atlético}

1: nenhuma dor e desempenho irrestrito

2: dor no esforço extremo e desempenho irrestrito

3: dor no esforço extremo ou após 1 a 2 horas da atividade, com desempenho normal ou levemente reduzido

4: dor durante e após qualquer atividade vigorosa e redução no desempenho

5: dor durante atividade esportiva forçando uma interrupção com diminuição acentuada do desempenho

6: dor durante AVD e incapacidade de praticar esportes

Figure 2. Final version of Classification for the Effect of Pain in Athletic Performance. 
Table I. General characteristics of the sample.

\begin{tabular}{ll}
\hline Characteristics of the sample & Mean \pm standard deviation \\
\hline Age (years) & $26.43 \pm 8.08$ \\
\hline Gender $(\mathrm{male} \%)$ & 61.90 \\
\hline Weight $(\mathrm{Kg})$ & $74.19 \pm 14.50$ \\
\hline Height $(\mathrm{m})$ & $1.73 \pm 0.09$ \\
\hline Duration of injury (months) & $35.46 \pm 47.71$ \\
\hline
\end{tabular}

Table II. Psychometric properties of the Tendon Grading System and Classification System for the Effect of Pain on Athletic Performance.

\begin{tabular}{ll}
\hline $\begin{array}{l}\text { Measurement properties - Validity } \\
\text { of construct (105 patients) }\end{array}$ & $\begin{array}{l}\text { Spearman correlation } \\
\text { coefficient (Rho) }\end{array}$ \\
\hline TGS & \\
\hline$\rho$, using VISA-A-Br as a comparison & $-0,794^{*}$ \\
\hline$\rho$, using o LEFS as a comparison & $-0,724^{*}$ \\
\hline CSEPAP & \\
\hline$\rho$, using VISA-A-Br as a comparison & $-0,809^{*}$ \\
\hline$\rho$, using LEFS as a comparison & $-0,678^{*}$ \\
\hline
\end{tabular}

TGS, Tendon Graduation System; VISA-A-Br, Victorian Institute of Sport Assessment - Achilles Questionnaire Brazilian Portuguese; CSEPAP, Classification for the Effect of Pain in Athletic Performance; LEFS, Lower Extremity Functional Scale. ${ }^{*} \varrho<0.05$.

the Effect of Pain on Athletic Performance and LEFS was - $0.68(\mathrm{p}=0.001)$ (table II), indicating a strong correlation. We confirmed 3 of the priori hypotheses, formulated resulting in $75 \%$ agreement.

\section{DISCUSSION}

The purpose of the study was to validate and culturally adapt the Tendon Grading System and Classification System for the Effect of Pain on Athletic Performance scales for the Brazilian Portuguese language. The results indicate that the Portuguese versions of the scales present idiomatic and semantic equivalence with the original English versions.

All steps proposed by the guidelines for transcultural adaptation of self-administered questionnaires were followed (14). The Delphi study provided the trusted opinion of a group of experts on the quality of translation. Although the sample from the risk group was higher than from the tendinopathy group, the number of participants was similar to other validation studies $(12,20)$. The pre-final versions of the scales were not tested in subjects with Achilles tendinopathy, but were applied to 25 healthy subjects to assess their comprehension of the scales. The scales were applied in a single moment. The Cronbach's alpha coefficient assesses internal consistency of a set of items, scale or subscale, corresponding to a single clinical dimension (21). Thus, the internal consistency could not evaluate because the two translated scales are composed by a single question (12). Baseline information and results were not divided into groups, but other studies support this analysis (8, $16,22,23)$.

The sample size of this research was compatible with the samples used in similar studies on translation and validation of functional scales. In addition, COSMIN recommendations address samples with at least 100 individuals in study designs like ours as satisfactory (17). The absence of others validation studies of these scales makes not possible to compare with other researches.

The Brazilian version of the Tendon Grading System and Classification System for the Effect of Pain on Athletic Performance scales presented satisfactory construct validity, as $75 \%$ of our hypotheses were met according to the criterion indicated by Terwee (17). Our findings corroborate information from the article by Robinson et al. that found a significant correlation between Classification System for the Effect of Pain on Athletic Performance and VISA-A in the English language versions (7).

Our article found a strong correlation between Tendon Grading System and VISA-A-Br. One possible explanation is that VISA-A-Br is a questionnaire that presents eight questions divided into three domains, pain, functional status, and activity (7), therefore, it evaluates the Achilles tendinopathy in a more specific manner. The Tendon Grading System covers all domains in only one item, so it is a broader classification. Our results are similar to those found in the original version of VISA-A, where a moderate correlation was found between Tendon Grading System and VISA-A (7).

The information provided by the LEFS and Classification System for the Effect of Pain on Athletic Performance scales would be complementary in the evaluation of an individual with Achilles tendinopathy. We highlight that VISA$\mathrm{A}-\mathrm{Br}$ is considered the most important scale for determining the severity of calcaneal tendon injuries (12) and has strong construct validity with the two scales translated. The Tendon Grading System and Classification System for the Effect of Pain on Athletic Performance are easy to apply and understand, providing an Achilles tendinopathy severity index with the advantage of being faster than the VISA-A. Therefore, the scales can be used to screen for the severity of Achilles tendinopathy more quickly and may obtain a similar result to the VISA-A-Br. 


\section{CONCLUSIONS}

We suggest that future studies be performed using the two scales as an outcome in the evaluation of individuals with Achilles tendinopathy. The Tendon Graduation System and Classification Scales for Effect of Athletic Performance Pain are similar to their original versions. The scales were valid for assessing pain and stiffness (Tendon Graduation System) and activity and participation (Classification Scales for Effect of Athletic Performance Pain) in the Brazilian population with Achilles tendinopathy.

\section{CONFLICT OF INTERESTS}

The authors declare that they have no conflict of interests.

\section{REFERENCES}

1. Sobhani S, Dekker R, Postema K, Dijkstra PU. Epidemiology of ankle and foot overuse injuries in sports: a systematic review. Scand J Med Sci Sports 2013;23:669-6.

2. Rompe JD, Furia JP, Maffulli N. Mid-portion Achilles tendinopathy--current options for treatment. Disability Rehab 2008;30(20-22):1666-76.

3. Gajhede-Knudsen M, Ekstrand J, Magnusson H, Maffulli N. Recurrence of Achilles tendon injuries in elite male football players is more common after early return to play: an 11-year follow-up of the UEFA Champions League injury study. Br J Sports Med 2013;47(12):763-8.

4. Albers IS, Zwerver J, Diercks RL, Dekker JH, Van den AkkerScheek I. Incidence and prevalence of lower extremity tendinopathy in a Dutch general practice population: a cross sectional study. BMC musculoskeletal disorders 2016;17:16.

5. de Jonge S, Van den Berg C, de Vos RJ, et al. Incidence of midportion Achilles tendinopathy in the general population. Br J Sports Med 2011;45(13):1026-8.

6. Martin RL, Chimenti R, Cuddeford T, Houck J, Matheson JW, McDonough CM, et al. Achilles Pain, Stiffness, and Muscle Power Deficits: Midportion Achilles Tendinopathy Revision 2018. J of Orthop sports Phys Ther 2018;48(5): A1-A38.

7. Robinson JM, Cook JL, Purdam C, et al. The VISA-A questionnaire: a valid and reliable index of the clinical severity of Achilles tendinopathy. Br J Sports Med 2001;35(5):335-41.

8. de Mesquita GN, de Oliveira MNM, Matoso AER, Filho AGM, de Oliveira RR. Cross-Cultural Adaptation and Measurement Properties of the Brazilian Portuguese Version of the Victorian Institute of Sport Assessment-Achilles (VISA-A) Questionnaire. J Orthop Sports Phys Ther 2018;24:1-24.

9. Percy EC, Conochie LB. The surgical treatment of ruptured tendo Achillis. Am J Sports Med 1978;6(3):132-6.
10. Curwin S, Stanish WD. Tendinitis: its etiology and treatment: Free Press 1984.

11. Silbernagel KG, Thomee R, Karlsson J. Cross-cultural adaptation of the VISA-A questionnaire, an index of clinical severity for patients with Achilles tendinopathy, with reliability, validity and structure evaluations. BMC musculoskeletal disorders 2005;6:12.

12. Lohrer H, Nauck T. Cross-cultural adaptation and validation of the VISA-A questionnaire for German-speaking achilles tendinopathy patients. BMC musculoskeletal disorders. 2009;10:134.

13. Padulo J, Oliva F, Frizziero A, Maffulli N. Muscles, Ligaments and Tendons Journal - Basic principles and recommendations in clinical and field Science Research: 2018 Update. Muscles Ligaments Tendons J 2018;8(3):305-7.

14. Beaton DE, Bombardier C, Guillemin F, Ferraz MB. Guidelines for the process of cross-cultural adaptation of self-report measures. Spine 2000;25(24):3186-91.

15. Hutchison AM, Evans R, Bodger O, et al. What is the best clinical test for Achilles tendinopathy? Foot and ankle surgery: official journal of the European Society of Foot and Ankle Surgeons 2013;19(2):112-7.

16. Pereira LM, Dias JM, Mazuquin BF, Castanhas LG, Menacho MO, Cardoso JR. Translation, cross-cultural adaptation and analysis of the psychometric properties of the lower extremity functional scale (LEFS): LEFS- BRAZIL. Braz J Phys Ther 2013;17(3):272-80.

17. Mokkink LB, Terwee CB, Knol DL, et al. The COSMIN checklist for evaluating the methodological quality of studies on measurement properties: a clarification of its content. BMC medical research methodology 2010;10:22.

18. Terwee CB, Bot SD, de Boer MR, et al. Quality criteria were proposed for measurement properties of health status questionnaires. J Clin Epidemiol 2007;60(1):34-42.

19. Cardoso FGC, Formiga C, Bizinotto T, Tessler RB, Rosa FN. Concurrent validity of the brunet-lezine scale with the bayley scale for assessment of the development of preterm infants up to two years. Revista paulista de pediatria: orgao oficial da Sociedade de Pediatria de Sao Paulo 2017;35(2):144-50.

20. Kaux JF, Julian OK, Dardenne N, et al. Validity and reliability of the French translation of the VISA-A questionnaire for Achilles tendinopathy. Disabil Rehabil 2016;38(26):2593-9.

21. Cronbach LJ, Meehl, PE. Construct validity in psychological tests. Psychol bulletin 1955;52(4):281.

22. Moreira TS, Magalhães LC, Silva RD, Martin RL, de Resende MA. Translation, cross-cultural adaptation and validity of the Brazilian version of the Foot and Ankle Ability Measure questionnaire. Disabil Rehabil 2016;38(25):2479-90.

23. Maffulli N, Longo UG, Testa V, Oliva F, Capasso G, Denaro V. Italian translation of the VISA-A score for tendinopathy of the main body of the Achilles tendon. Desabil Reabil 2008;30:1635-9. 